\title{
HEALTH SURVEY OF WILD AND CAPTIVE BOG TURTLES (CLEMMYS MUHLENBERGII) IN NORTH CAROLINA AND VIRGINIA
}

\author{
Deena Brenner, B.S., Gregory Lewbart, M.S., V.M.D., Dipl. A.C.Z.M., Martha Stebbins, D.V.M., \\ Ph.D., Dipl. A.C.V.P.M., and Dennis W. Herman, B.S.
}

\begin{abstract}
Blood samples, fecal samples, and cloacal swabs were collected from 42 bog turtles (Clemmys muhlenbergii), including 14 wild males, 22 wild females, three captive males, and three captive females, in Virginia and North Carolina, USA. Samples were analyzed for hematologic and plasma chemistry values, Mycoplasma sp. antibodies, intestinal parasites, and normal cloacal flora.

Key words: Clemmys muhlenbergii, turtle, hematology, Mycoplasma sp., parasitology.
\end{abstract}

\section{INTRODUCTION}

Bog turtles (Clemmys muhlenbergii) are the smallest and rarest turtles in North America. Scattered populations exist in open sedge meadows, wet pastures, and small isolated fens and shrub bogs from Massachusetts to northeastern Georgia. ${ }^{9} 14$ In 1997, bog turtles were federally listed as a threatened species under the Endangered Species Act. ${ }^{4}$ Although there has been a great deal of natural history research performed, baseline medical data are lacking for this species. In this study, hematologic and plasma chemistry reference values were established for captive and wild bog turtle populations. Representative blood samples were also submitted for Mycoplasma sp. screening, and turtles were tested for intestinal parasites and cloacal flora. It is hoped that this clinical information will contribute to the protection and management of this species.

\section{MATERIALS AND METHODS}

Samples were collected from six captive bog turtles (including three males and three females) at the North Carolina Museum of Natural Sciences in Raleigh, North Carolina. Samples were also collected from 28 wild individuals (including 11 males and 17 females) at seven sites in three North Carolina counties and from eight wild individuals (three males and five females) at three sites in two counties in Virginia. Specific coordinates of these sites are not provided because of the protected status of these animals. Samples were collected during 8 days in May, June, and July 2001. Ambient tem-

From the College of Veterinary Medicine, North Carolina State University, 4700 Hillsborough Street, Raleigh, North Carolina 27606, USA (Brenner, Lewbart, Stebbins); and Project Bog Turtle, North Carolina Museum of Natural Sciences, 11 West Jones Street, Raleigh, North Carolina 27601-1029, USA (Herman). Correspondence should be directed to Dr. Lewbart. perature was $15-25^{\circ} \mathrm{C}$, and weather conditions varied from rainy to sunny during the collection period. Wild bog turtles were located primarily by visual search or by probing with a stick within a muddy pocket. Turtles were weighed, measured, sexed, and scanned for the presence of a passive integrated transponder (PIT-tags). If no transponder was found in North Carolina turtles with carapace lengths $>50$ $\mathrm{mm}$, one was implanted within the coelomic cavity. The implantation site was closed with cyanoacrylate ester surgical tissue adhesive (Duro ${ }^{\circledR}$, Loctite Corporation, Rocky Hill, Connecticut 06067, USA). Turtles were also palpated for the presence of shelled (calcified) eggs and enlarged follicles (yolks) by gently massaging the area near and around the ovaries and oviducts with fingertips. A blood sample (approximately $0.5 \%$ of body weight) was collected from 33 turtles from the occipital sinus using a 27-gauge needle and a sodium-heparinized, 1-ml tuberculin syringe (Monoject ${ }^{\circledR}$, Sherwood Medical, St. Louis, Missouri 63103, USA). The occipital sinus is located at the base of the skull, just caudal to the occipital protuberance. ${ }^{13}$ The site was approached by extending the neck and tilting the head ventrally approximately $90^{\circ}$. Two blood smear slides were made for each turtle immediately after blood collection for complete blood cell count (CBC) analysis. Slides were air-dried and placed in cardboard holders. Two heparinized microhematocrit capillary tubes (Fisher Scientific Co., Pittsburgh, Pennsylvania 15219, USA) were filled for each turtle to establish the packed cell volume (PCV). The remaining blood was placed in lithiumheparinized plasma separator tubes (Microtainer ${ }^{\circledR}$ Brand, Becton Dickinson and Co., Franklin Lakes, New Jersey 07417-1885, USA) or in snap tubes for plasma chemistry analysis. Seven blood samples (approximately one sample per site) were sent to the University of Florida, College of Veterinary Medicine, Mycoplasma Research Laboratory for 
analysis using an enzyme-linked immunosorbent assay to test for the presence of M. agassizii antibodies. These samples were stored at $-20^{\circ} \mathrm{C}$ until analysis.

Blood for plasma chemistry analysis was placed on ice until centrifuged approximately $6-8 \mathrm{hr}$ after collection. Cloacal swabs for bacterial culture (BBL ${ }^{\text {(ixi }}$, Culture Swab ${ }^{\text {(ix }}$, or BBL Minitip Culturette ${ }^{\text {(ix) }}$, Becton Dickinson and Co., Sparks, Maryland 21152, USA) were taken from 31 turtles after cleaning the cloaca with an alcohol pad. Fecal samples were collected from 29 turtles by flushing their cloacae and distal intestinal tracts with approximately $7 \mathrm{ml}$ of sterile saline through a lubricated size 5 French rubber catheter (Sherwood Medical). Samples were collected by the free-catch method.

All blood samples for hematologic and plasma chemistry analysis, cloacal swabs, and fecal samples were sent by overnight courier to Antech Diagnostics Lab (Southaven, Mississippi 38671, USA), except for samples from seven turtles (six blood samples, seven fecal samples, seven cloacal swabs), which were sent through the United States Postal Service and were lost for 9 days. The data collected from these samples are included in Table 1 , and statistically significant differences are given in Results. Samples were stored at approximately $20^{\circ} \mathrm{C}$ in the laboratory, for a maximum of $12 \mathrm{hr}$ until analysis. Packed cell volume, blood parasite check, and CBC, including estimated white blood cell count (WBCs), heterophil count, absolute heterophil count, lymphocyte count, absolute lymphocyte count, monocyte count, absolute monocyte count, eosinophil count, absolute eosinophil count, basophil count, absolute basophil count, and cell morphology, were measured using blood smear slides stained with Wright-Giemsa (Fisher Scientific Co.) at $\times 100$ magnification. One hundred leukocytes were manually counted per slide. The PCV was established by centrifuging the blood in heparinized microhematocrit tubes for 5 min using a microhematocrit centrifuge (IEC, Needham Heights, Massachusetts 02494, USA). The WBC estimate was determined by examining 10 different fields at $\times 50$ magnification, taking the average of the fields and multiplying by 2,000 (equivalent to the Eosinophil Unopette technique). ${ }^{11}$ Plasma chemistry analysis, including glucose, blood urea nitrogen (BUN), total protein, albumin, aspartate aminotransferase, $\mathrm{Ca}, \mathrm{P}, \mathrm{Na}, \mathrm{K}, \mathrm{Cl}$, globulin, creatinine phosphokinase (CPK), and uric acid, was performed using a Hitachi 717 autoanalyzer (Hitachi Instruments Inc., San Jose, California 95134, USA). Protein electrophoresis was performed to distinguish the albumin and globulin fractions, using a
Clinical Appraise ${ }^{\circledR}$ Densitometer (Beckman Coulter, Fullerton, California 92834-3100, USA).

Hematology and plasma chemistry values were analyzed for statistical significance $(P \leq(0.05)$ between captive bog turtles and wild bog turtles, males and females, and wild females and wild males. Analysis of wild females versus captive females or wild males versus captive males was not performed because the captive sample size was too small to produce valid statistical results. Nonparametric statistical tests were performed using Analyse-It ${ }^{\circledR}$ version 1.61 (Analyse-It Software Ltd., Leeds LS12 5XA, England, UK).

Cloacal swabs were placed in either Stuart's media or sterile saline after collection and stored at room temperature before shipment. Swabs were then plated on MacConkey agar and trypticase soy agar with 5\% sheep blood. Swabs were also dipped in Selenite broth. Plates and broth were incubated at $37 \pm 2^{\circ} \mathrm{C}$ for $24-48 \mathrm{hr}$. In samples showing bacterial growth, samples were subcultured using a biplate of Hektoen enteric and Salmonella and Shigella agar. Antibiotic sensitivities were determined by the Kirby-Bauer method.

Fecal samples were processed using a fecal float method with a sodium nitrite solution (Fecal-Med, First Priority, Inc., Elgin, Illinois 60123, USA). Slides were screened for helminth ova and parasites at $\times 100$ and confirmed at $\times 400$ magnification with an Olympus light microscope (Olympus Scientific Instruments, Melville, New York 11747-3157, USA). One sample that contained an unidentifiable protozoan was sent to Cornell University, School of Veterinary Medicine, Parasitology Laboratory for further analysis. This included additional floatation in zinc sulfate solution and in sugar solution, followed by benchtop centrifugation (Daimon/IEC). Slides were then examined at $\times 100$ and $\times 400$ magnification (Zeiss, Thornwood, New York 10594, USA).

\section{RESULTS}

\section{Physical examination}

On gross physical examination, all except one bog turtle appeared in good condition. This turtle was part of the North Carolina Museum of Natural Sciences collection and presented with swollen, discolored limbs. The turtle died on 21 May 2001 and was diagnosed at necropsy with chronic-active nephritis with tubular mineralization and membranous glomerulopathy, chronic interstitial pneumonia, testicular atrophy and mineralization, and pancreatic atrophy. Body weights of 33 of the sampled wild bog turtles were $55-176 \mathrm{~g}(\bar{x}=135.15 \pm 20.75 \mathrm{~g})$. 


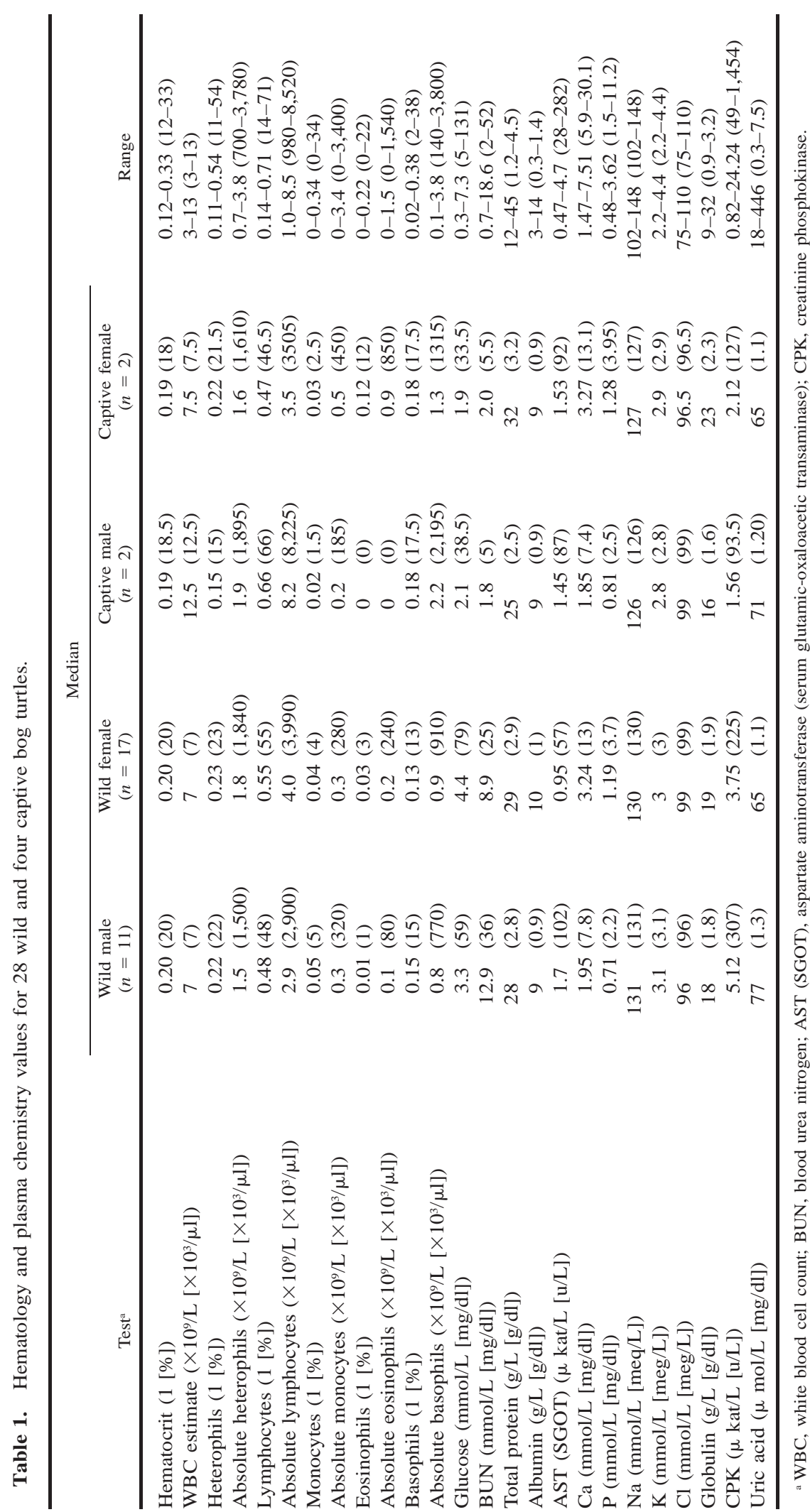


Various abnormalities, such as stubbed tails, missing toes, shell deformities, and shell asymmetries, were found among the wild bog turtle populations. Twelve out of 18 wild females were found to be gravid by palpation, three with shelled eggs and nine with unshelled eggs.

Hematology and plasma chemistry values: Results of hematology and plasma chemistry analyses are listed in Table 1. Captive bog turtles had a higher estimated WBC count than did wild bog turtles $\left(\right.$ median $=10 \times 10^{9} / \mathrm{L}\left[10 \times 10^{3} / \mu 1\right]$ in captive turtles versus $7 \times 10^{9} / \mathrm{L}\left[7.0 \times 10^{3} / \mu \mathrm{l}\right]$ in wild turtles, $P=0.0255)$. Compared with captive turtles, wild bog turtles had a higher percentage of heterophils (median $=0.23[23.0 \%]$ in wild turtles versus 0.19 [19.0\%] in captive turtles, $P=0.0234$ ) and higher BUN levels (median $=9.8 \mathrm{mmol} / \mathrm{L}$ [27.5 mg/dl] in wild turtles versus $1.8 \mathrm{mmol} / \mathrm{L}$ [5.0 $\mathrm{mg} / \mathrm{dl}]$ in captive turtles, $P=0.0004)$. Wild bog turtles had significantly higher levels of $\mathrm{Na}(P=$ $0.0292)$ and $\mathrm{K}(P=0.0482)$ than did captive bog turtles when the lost samples were removed from the data set.

Compared with male bog turtles, female bog turtles had a higher percentage of eosinophils (median $=0.03[3.0 \%]$ in females versus $0.01[1.0 \%]$ in males, $P=0.0472$ ), a higher absolute eosinophil count $\left(\right.$ median $=0.2 \times 10^{9} / \mathrm{L}[240.0 / \mu 1]$ in females versus $0.1 \times 10^{9} / \mathrm{L}[70.0 / \mu 1]$ in males, $\left.P=0.0266\right)$, higher $\mathrm{Ca}$ levels (median $=3.24 \mathrm{mmol} / \mathrm{L}[13.0 \mathrm{mg} /$ dl] in females versus $1.92 \mathrm{mmol} / \mathrm{L}[7.7 \mathrm{mg} / \mathrm{dl}]$ in males, $P<0.0001$ ), and higher $\mathrm{P}$ levels (median $=$ $1.19 \mathrm{mmol} / \mathrm{L}[3.7 \mathrm{mg} / \mathrm{dl}]$ in females versus 0.74 $\mathrm{mmol} / \mathrm{L}[2.3 \mathrm{mg} / \mathrm{dl}]$ in males, $P=0.0102)$. These statistically significant differences between female and male bog turtles remained significant when the lost samples were removed from the data set.

Compared with wild males, wild females had higher Ca levels (median $=3.24 \mathrm{mmol} / \mathrm{L}[13.0 \mathrm{mg}$ / dl] in females versus $1.95 \mathrm{mmol} / \mathrm{L}[7.8 \mathrm{mg} / \mathrm{dl}]$ in males, $P=0.0001$ ), higher $\mathrm{P}$ levels (median $=1.19$ $\mathrm{mmol} / \mathrm{L}[3.7 \mathrm{mg} / \mathrm{dl}]$ in females versus $0.71 \mathrm{mmol} /$ $\mathrm{L}[2.2 \mathrm{mg} / \mathrm{dl}]$ in males, $P=0.0185)$, and a higher absolute lymphocyte count $\left(\right.$ median $=4.0 \times 10^{9} / \mathrm{L}$ $[3,990 / \mu \mathrm{l}]$ in females versus $2.9 \times 10^{9} / \mathrm{L}[2,900 / \mu \mathrm{l}]$ in males, $P=0.0239$ ). Compared with wild females, wild males had higher BUN levels (median $=12.9 \mathrm{mmol} / \mathrm{L}[36.0 \mathrm{mg} / \mathrm{dl}]$ in males versus 8.9 $\mathrm{mmol} / \mathrm{L}[25.0 \mathrm{mg} / \mathrm{dl}]$ in females, $P=0.034)$. But statistical significance in BUN levels was not found between wild males and wild females when the lost samples were removed from the data set. Slight anisocytosis was noted in three turtles, slight polychromasia in two turtles, slight anisocytosis accompanied by moderate polychromasia and many early erythroid cells in four turtles, and slight polychromasia accompanied by few early erythroid cells in one turtle. Azurophilic monocytes were found in all but one turtle. No blood parasites were seen on the blood smear slides.

Serology: All seven of the blood samples sent to the University of Florida were found negative for M. agassizii antibodies.

Parasites: Caryospora sp. were found in a fecal sample from one bog turtle in North Carolina. All other fecal samples from wild and captive bog turtles were free from intestinal parasites and helminth ova.

Cloacal swabs: Nonpathogenic Enterococcus sp. was isolated in one turtle in North Carolina and produced scant growth on blood agar. Aeromonas sp. and Enterobacter sp. were isolated in another turtle in North Carolina and produced heavy growth on blood agar, MacConkey agar, and Hektoen enteric Salmonella and Shigella agar (Aeromonas sp. only). The Aeromonas sp. and Enterobacter sp. were sensitive to amikacin, chloramphenicol, ciprofloxacin, cefotaxime, doxycycline, enrofloxacin, gentomycin, orbifloxacin, and piperacillin and were resistant to cephalothin and penicillin. Aeromonas sp. was also resistant to trimethoprim-sulfamethoxazole, whereas Enterobacter sp. was sensitive to trimethoprim-sulfamethoxazole. Salmonella sp. and Shigella sp. were not isolated from any of the bog turtle cloacal swabs.

\section{DISCUSSION}

Female bog turtles had higher $\mathrm{Ca}$ and $\mathrm{P}$ levels than did male bog turtles, which may be due to the time of year when these samples were collected. Increased calcium levels are accurate indicators of vitellogenesis and follicular growth in the desert tortoise (Gopherus agassizii), the Galapagos tortoise (Geochelone nigra), and the Kemp's ridley sea turtle (Lepidochelys kempi). ${ }^{11-19}$ Although the closely related spotted turtle (Clemmys guttata) experiences slow vitellogenesis continuously throughout the year, rapid vitellogenesis may occur just before ovulation. ${ }^{7}$ Female bog turtles lay their eggs from mid-May to mid-July, and most of the wild female bog turtles found were gravid with shelled or unshelled eggs. Significant differences in $\mathrm{Ca}$ levels between males and females have also been reported in free-ranging pancake tortoises (Malacochersus tornieri) and captive New Guinea snapping turtles (Elseya novaeguineae). ${ }^{1,15}$

Urea nitrogen levels were significantly higher in wild bog turtles than in captive bog turtles. Within the wild population, males had significantly higher BUN levels than did females. This difference no 
longer existed when the lost samples were eliminated from the data set. Elevated BUN levels can indicate dehydration or a high-protein diet. It is not believed that these animals were dehydrated. Although it has not been documented, if wild males were to consume a higher-protein diet than do wild females, they could have higher BUN levels. It is also possible that wild bog turtles simply consume a higher-protein diet than do captive turtles.

Although captive bog turtles had significantly higher estimated WBC counts than did wild turtles, wild bog turtles had a higher percentage of heterophils than did captive turtles. Male and female bog turtles did not vary significantly in WBC count or percentage of heterophils. When the data from the deceased captive turtles was removed, wild bog turtles had statistically higher BUN levels, a higher percentage of monocytes, and a higher concentration of CPK than did captive bog turtles. It is possible that the increased CPK levels resulted from muscle damage or overexertion in active wild bog turtles. Sodium and $\mathrm{P}$ levels were significantly higher in wild bog turtles when the lost samples were removed from the data set. This may be an indicator of dehydration. Although female bog turtles had a higher absolute eosinophil count and a higher percentage of eosinophils than did male bog turtles, wild females were not significantly different from wild males. The data suggest that captive females have higher eosinophil counts than do captive males. But blood samples were only collected from two captive females, one of which had an eosinophil count more than twice that of any other bog turtle. Wild females were found to have a significantly higher lymphocyte count compared with wild males, as has been found in other reptilian species. $^{6}$

Mycoplasma sp. antibodies have been found in gopher tortoises (Gopherus polyphemus), desert tortoises, and eastern box turtles (Terrapene carolina carolina) but have not been reported in bog turtles ${ }^{5,10,12}$ and were not detected in this study.

Parasites were markedly absent in bog turtle fecal samples. Only one parasite, the cyst-forming coccidian Caryospora sp., was noted in one of the 29 fecal samples. Caryospora sp. has been found in green sea turtles (Chelonia mydas) and a host of other reptiles. ${ }^{8}$

Bog turtles live primarily in areas rich with sphagnum moss, which may have antibacterial properties. ${ }^{2,3}$ It is possible that handling, shipping, culture technique, and alcohol preparation of the site also may have contributed to the small number of positive samples. Salmonella sp. and Shigella sp. were not found in any cloacal swabs. Enterococcus sp. was found in one sample and may be part of the normal flora. Aeromonas sp. and Enterobactor sp. were seen in one sample. These bacteria are commonly isolated from healthy reptiles but under certain situations may become opportunistic pathogens.

These results should not be accepted as normal values for all bog turtles because they were obtained from a small sample of turtles at one time of the year. It is likely that there is considerable seasonal variation and variation between sexes throughout the year. It is also probable that values will vary between northern and southern populations of bog turtles.

Acknowledgments: We thank the members of Project Bog Turtle, especially Jeff Beane, John Cecil, Bob Davis, Dan Dombrowski, Tom Henson, Chris McGrath, Tammy Sawyer, Ann B. Somers, Tom Thorp, Bern Tryon, Jim Warner, and Joe Zawadowski, for expertise and assistance. Samples were collected under endangered species permits issued by the North Carolina Wildlife Resources Commission (Permit No. NC-2001-ES-62) and the Virginia Department of Game and Inland Fisheries (Permit No. 017465). We thank Mike Pinder for allowing this research to take place in Virginia. We thank Maureen Trogdon for all her help with the supplies, samples, and shipping. We thank the North Carolina State University, College of Veterinary Medicine and Project Bog Turtle for funding.

\section{LITERATURE CITED}

1. Anderson, N. L., R. F. Wack, and R. Hatcher. 1997. Hematology and clinical chemistry reference ranges for clinically normal, captive New Guinea snapping turtle ( $E l$ seya novaeguineae) and the effects of temperature, sex, and sample type. J. Zoo Wildl. Med. 28: 394-403.

2. Basile, A., S. Giordano, J. A. Lopez-Saez, and R. C. Cobianchi. 1999. Antibacterial activity of pure flavanoids isolated from mosses. Phytochemistry 52: 1479-1482.

3. Basile, A., S. Sorbo, S. Giordano, A. Lavitola, and R. Cobianchi Castaldo. 1998. Antibacterial activity in Pleurochaete squarrosa extract (Bryophyta). Int. J. Antimicrob Agents 10: 169-172.

4. Beane, J. 2001. The Stick People. Wildl. N. C. 65: 14-19.

5. Calle, P. P., J. L. Behler, J. McDougal, S. M. Lee, I. M. Schumacher, and D. R. Brown. 1998. Mycoplasma survey of captive and free-ranging eastern box turtles (Terrapene carolina carolina) in New York. Proc. Am. Assoc. Zoo Vet./Am. Assoc. Wildl. Vet. 1998: 285-287.

6. Campbell, T. W. 1996. Clinical pathology. In: Mader, D. R. (ed.). Reptile Medicine and Surgery. W. B. Saunders Co., Philadelphia, Pennsylvania. Pp. 248-257.

7. Ernst, C. H., and G. R. Zug. 1994. Observation on the reproductive biology of the spotted turtle, Clemmys 
guttata, in southeastern Pennsylvania. J. Herpetol. 28: 99102.

8. Gordon, A. N., W. R. Kelly, and R. J. G. Lester. 1993. Epizootic mortality of free-living green turtles, Chelonia mydas, due to coccidiosis. J. Wildl. Dis. 29: 490493.

9. Herman, D. W., and B. W. Tryon. 1997. Land use, development, and natural succession and their effects on bog turtle habitat in the southeastern United States. In: J. Van Abbema (ed.). Proceedings: Conservation, Restoration, and Management of Tortoises and Turtles-An International Conference; July 1993; Purchase, New York. Wildlife Conservation Society Turtle Recovery Program and the New York Turtle and Tortoise Society, New York, New York. Pp. 364-371.

10. Homer, B. L., K. H. Berry, M. B. Brown, G. Ellis, and E. R. Jacobson. 1998. Pathology of diseases in wild desert tortoises from California. J. Wildl. Dis. 34: 508523.

11. Lawton, M. P., S. J. Divers, and F. Gordon. 1999. Comparison of leukocyte counts using two different methods. Proc. Assoc. Rep. Amphib. Vet. 1999: 149-152.

12. McLaughlin, G. S., E. R. Jacobson, D. R. Brown, C. E. McKenna, I. M. Schumacher, H. P. Adams, M. B. Brown, and P. A. Klein. 2000. Pathology of upper respiratory tract disease of gopher tortoises in Florida. J. Wildl. Dis. 36: 272-283.
13. Murray, M. 2000. Reptilian blood sampling and artifact considerations. In: A. M. Fudge (ed.). Laboratory Medicine: Avian and Exotic Pets. W. B. Saunders Co., Philadelphia, Pennsylvania. Pp. 185-192.

14. Palmer, W. M., and A. L. Braswell. 1995. The Reptiles of North Carolina. Univ. of North Carolina Press, Chapel Hill, North Carolina.

15. Raphael, B. L., M. W. Klemens, P. Moehlman, E. Dierenfeld, and W. B. Karesh. 1994. Blood values in freeranging pancake tortoises (Malacochersus tornieri). J. Zoo Wildl. Med. 25: 63-67.

16. Redrobe, S., and J. MacDonald. 1999. Sample collection and clinical pathology of reptiles. Vet. Clin. N. Am. Exotic Anim. Pract. 2: 709-730.

17. Rostal, D. C., V. A. Lance, J. S. Grumbles, and A. C. Alberts. 1994. Seasonal reproductive cycle of the desert tortoise (Gopherus agassizii) in the eastern Mohave Desert. Herpetol. Monogr. 8: 72-82.

18. Rostal, D. C., D. W. Owens, J. S. Grumbles, D. S. MacKenzie, and M. S. Amoss. 1998. Seasonal reproduction cycle of the Kemp's ridley sea turtle (Lepidochelys kempi). Gen. Comp. Endocrinol. 109: 232-243.

19. Rostal, D. C., T. R. Robeck, J. S. Grumbles, P. M. Burchfield, and D. W. Owens. 1998. Seasonal reproductive cycle of the Galapagos tortoise (Geochelone nigra) in captivity. Zoo Biol. 17: 505-517.

Received for publication 17 January 2002 